of purely local significance ; the supervision of village forests ; the creation of plantations of fast-growing trees for supplies of building poles and firewood necessary for the economy of rural areas and minor townships ... etc." Also, the local government should take over the management of all natural tree growth on Crown lands. The report continues: "Although it is a prior condition that the local government shall have the will and competency to undertake the additional duties attendant on devolution, it is a disagreeable fact that no local government has as yet the competency. The management of local forestry is still very largely the concern of the District Forest Officers, and local staffs are for the most part painfully inadequate. Few local governments are able to pay wages comparable with those given by the Protectorate; and even if suitable men are produced for training, they are young men who lack experience and consequently lack authority with chiefs and the people. In many districts the only alternative appears to be to second Protectorate Rangers". The management of the classes of forest herein contemplated, which are of primary importance to the local communities, is very far from being the easy or simple job which the Civil departments of the British Administration have so often regarded it in the past. The trained forest officer's job was, and is, considered to be in the big forests from which timber and revenue comeotherwise the Department is not paying its way.

In some parts of the world, by no means confined to the British Commonwealth, there are large populations living in hot countries where over great tracts of land the forest is represented by a scrub of varying height, growth, consistency and species, with grass for grazing, and so forth, the maintenance of which is essential to the well-being of the local populations and to their agricultural occupations. The continuance and, if possible, improvement of this type of forest, for forest it is, are as vital in the administration of the country as are the big timber forests, and demand often the highest skill of the trained and experienced forest officer-the district forest officer alluded to in the Uganda report. Such knowledge is not possessed by the Civil authority, nor by village communities, and to apply it requires a greater authority than that of a Protectorate ranger.

E. P. Stebing

\section{THE OPENING OF MILK BOTTLES BY BIRDS}

$\mathrm{T}$ $\mathrm{HE}$ opening of milk bottles by birds is now a well-known habit throughout most of the British Isles and has previously been described in Nature $(165,435 ; 1950)$. Further information has now been collected by R. A. Hinde and James Fisher, and includes records from the British Isles and other countries (British Birds, 44, No. 12; 1952).

In Sweden, as in Britain, observations have been made of the opening of milk bottles by blue tits and great tits. The habit is said to be widespread and that "magpies and blackbirds" also raided the bottles. In Vendolso tits have been observed opening coffee cream bottles. In Denmark the habit is also well known, and, in suburban districts, is said to be almost a nuisance; the main birds are the great tit and the great spotted woodpecker (Dendrocopus major). In Copenhagen the opening of bottles by great spotted woodpeckers is reported to be a general practice. Along the south border of the Geel forest jackdaws have been seen opening bottles.

Inquiries made by Dr. L. Tinbergen in Holland indicate that bottle opening occurs in at least twenty-one localities south of the Zuider Zee ; in all cases where the bird was certainly identified it was a great tit. Milk bottles practically disappeared from Holland during the War and only became reasonably common again in 1947-48. It is unlikely that many tits which had learnt the habit in pre-war years still survived at this date, so the habit must have originated in all the recorded localities since 1948. Since great tits are relatively sedentary birds, it seems certain that the habit was started in many different places and by many individuals.

In the United States a photograph of a Steller's jay (Cyanocitta stelleri) opening a milk bottle has appeared in a Seattle newspaper.

Although no experimental analysis of the behaviour involved in the opening of milk bottles has yet been made, further observations in the field enable the discussion to be carried further. Previously the processes were considered in two parts - the 'recognition' of the milk bottle as a potential supply of food and the technique of opening the bottle. The actual opening of the bottle probably depends on innate motor patterns, and the study of tits in the field has confirmed this view. The movements used are the same as those used when feeding on natural foods. For example, the hammering action with which foil caps are punctured is very similar to a motor pattern used in opening nuts, and the tearing action often used on cardboard tops is similar to a movement used in tearing bark from a twig.

It has been suggested that the initial 'discovery' of the bottle as a source of food may be a logical consequence of the feeding habits of tits. They appear to have an inborn tendency to inspect a great variety of conspicuous objects which contrast with their surroundings, and to test their palatability. If the outside of the object is unpalatable, they may attempt to open it by hammering - hammering seems to be evoked by the sound of a hollow object. In fact, it seems that, when tits are looking for food, objects with certain very general characteristics may be sufficient to release a more limited type of searching behaviour (such as flying to the food). By a succession of similar steps (hammering, etc.), evoked by successively more specific stimuli, a reward may eventually be obtained. It so happens that milk bottles have sufficient characteristics in common with the natural foods for tits occasionally to 'discover' them in the course of their normal searching.

When a bird has fed once or a few times at milk bottles, it will learn to return to them on later occasions, presumably by a form of trial-and-error learning. On these subsequent occasions the bird may come to respond to quite different stimuli from those which controlled its behaviour the first time. For example, if milk bottles with differently coloured stoppers are available, the tits will often concentrate their attacks on those having stoppers of one particular colour - presumably because the colour of the top was one of the characters which the bird learnt on the first visits.

Hinde and Fisher also suggest that the apparent copying of the behaviour by other individuals is probably due to another process-local enhancement - which modifies the appetitive behaviour of feeding and is initially independent of reward. 